\title{
Peningkatan Proses Pembelajaran Melalui Pelatihan Kuliah Online Bagi Dosen
}

\author{
Febri Liantoni ${ }^{1}$, Rachman Arief ${ }^{2}$, Nanang Fakhrur Rozi ${ }^{3}$, Anwar Sodik ${ }^{4}$ \\ 1, 2, 3,4 Institut Teknologi Adhi Tama Surabaya
}

\begin{tabular}{|c|c|}
\hline Article History & ABSTRACT \\
\hline \multirow[t]{2}{*}{$\begin{array}{l}\text { Received 12.09.2018 } \\
\text { Received in revised form } \\
01.12 .2018 \\
\text { Accepted } 31.03 .2019 \\
\text { Available online } 02.04 .2019\end{array}$} & $\begin{array}{l}\text { IMPROVING LEARNING PROCESSES THROUGH ONLINE LECTURE } \\
\text { TRAINING FOR LECTURERS. The development of information and } \\
\text { communication technology sophistication is undeniable. One form of } \\
\text { technological development is the Internet. With the Internet, we can receive } \\
\text { and access information in various formats from all corners of the world. The } \\
\text { presence of the Internet provides convenience in the world of education as a } \\
\text { learning medium. Based on these conditions, online lecture training is } \\
\text { conducted with the aim of improving the learning process during lectures. } \\
\text { The training was conducted with the Google Classroom application } \\
\text { introduction material. The results obtained during the training showed very } \\
\text { high lecturer enthusiasm. Training makes lecturers have the ability to better } \\
\text { manage lecture materials, can arrange quiz schedules or assignments } \\
\text { regularly every week, the ability of lecturers in interpersonal communication } \\
\text { also increases with class collaboration. }\end{array}$ \\
\hline & $\begin{array}{l}\text { Keywords: Google Classroom, Information and Communication Technology, } \\
\text { Lecturer. }\end{array}$ \\
\hline
\end{tabular}

DOI: $10.30653 / 002.201941 .65$

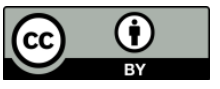

This is an open access article distributed under the terms of the Creative Commons Attribution 4.0 International License, which permits unrestricted use, distribution, and reproduction in any medium, provided the original work is properly cited. ๑) 2019 Febri Liantoni, Rachman Arief, Nanang Fakhrur Rozi, Anwar Sodik.

\section{PENDAHULUAN}

Perguruan tinggi merupakan lembaga pendidikan tinggi yang memiliki tugas dan fungsi melaksanakan proses pembelajaran yang optimal. Hal ini menjadi upaya menciptakan lulusan yang berkualifikasi standar nasional. Pelaksanaan pembelajaran dalam rangka melaksanakan tugas Tri Darma perguruan tinggi yang harus memperhatikan kualitas dosen dalam merencanakan, melakukan, dan menilai proses Tri Darma perguruan tinggi.

Institut Teknologi Adhi Tama Surabaya (ITATS) sebagai salah satu perguruan tinggi di kota Surabaya yang memiliki tekad menjadi lembaga unggul dan mejadi rujukan dalam inovasi belajar. Untuk mewujudkan visi tersebut ITATS fokus dalam program

${ }^{1}$ Corresponding author: Program Studi Teknik Informatika, Fakultas Teknologi Informasi, Institut Teknologi Adhi Tama Surabaya; Jalan Arief Rachman Hakim 100, Surabaya; Email: febri.liantoni@itats.ac.id 
peningkatan kualitas dosen salah satunya melalui pembelajaran online. Untuk meningkatkan proses pembelajaran tersebut salah satu yang bisa digunakan dengan memanfaatkan teknologi yang sudah berkembang sangat pesat. Kemajuan teknologi ini berdampak pada semua aspek kehidupan yang berhubungan dengan dunia informasi dan teknologi. Salah satu bentuk perkembangan teknologi adalah Internet. Dengan internet kita dapat mengetahui berbagai informasi yang tersebar di berbagai negara.

Media pembelajaran sendiri juga memiliki peran yang sangat singnifikan dalam menentukan kelancaran proses perkuliahan (Kurnia \& Nugroho, 2017; Asyhar, 2012). Media pembelajaran dapat berupa teknologi, salah satunya memanfaatkan internet. Penerapan media pembelajaran sangat membantu keberhasilan dalam proses belajar mengajar (Muslih, 2016). Proses pembelajaran melalui media internet sudah sering dilakukan diberbagai institusi. Hal ini bertujuan untuk meningkatkan kemandirian belajar mahasiswa melalui media pembelajaran seperti virtual class (Sohibun \& Ade, 2017). Salah satu media yang digunakan yaitu Google drive yang berguna untuk berbagi dokumen. Penggunaan media pembelajaran bisa membangkitkan keinginan, minat baru, dapat memotivasi dan merangsang kegiatan belajar bahkan mempengarui psikologis peserta didik (Sari, 2016).

Proses pembelajaran di ITATS, antara lain dengan melakukan tatap muka dosen dan mahasiswa dalam satu semester sebanyak 14 kali pertemuan selama 14 minggu. Jika berhalangan hadir tidak bisa melakukan perkuliahan, maka dosen harus mengganti di waktu lain. Untuk mengatasi kondisi dimana jika susah mencari waktu luang sebagai pengganti, maka dosen bisa melakukan pertemuan dengan mahasiswa melalui kuliah online. Oleh sebab itu maka diadakan pelatihan kuliah online bagi dosen ITATS.

Pada pelatihan ini diterapkan pembelajaran dalam jaringan (daring) yang memanfaatkan salah satu aplikasi google kelas (classroom.google.com) dengan pendekatan model pembelajaran kolaboratif. Dengan menggunakan aplikasi ini dosen dapat memeberikan materi secara daring sehingga mahasiswa dapat mendapatkan materi dengan lebih mudah. Proses pemberian tugas dan kuis dapat juga dilakukan secara online akan mempermudah proses belajar mengajar. Mahasiswa dapat memberikan pertanyaan langsung melalui komentar pada materi yang belum dipahami. Mahasiswa lain juga dapat saling berinteraksi satu dengan lainnya, sehingga diskusi kelas bisa berjalan dengan baik. Pelatihan dilakukan selama dua hari dan dibagi menjadi empat sesi untuk semua dosen ITATS.

\section{METODE PELAKSANAAN}

Pelaksanaan proses pembelajaran dengan memanfaatkan penggabungan komputer dengan teknologi dalam bidang telekomunikasi (internet) telah menjadikan manusia ke era informasi yang maju. Teknologi informasi dan komunikasi (TIK) ini telah banyak memberikan kontribusi dalam proses pembelajaran di dunia pendidikan tinggi. Pengguna TIK sendiri sangat menyebar luas mulai dari kalangan dewasa, remaja, bahkan anak-anak.

Pada kegiatan pelatihan proses pembelajaran bagi dosen ini dilakukan dengan memanfaatkan teknologi sebagai metoda pembelajaran e-learning khususnya dengan aplikasi Google. Melalui e-learning mahasiswa dituntut lebih aktif dalam menerima materi kuliah. Penggunaan e-learning lebih efisien karena tidak menuntut waktu dan tempat (Eliana, Senam, \& Jumaidi, 2016; Buntoro, Ariyadi, \& Astuti, 2018). 
Google Classroom mengikat Google Drive, Google Dokumen, Spreadsheet, dan Slide, dan Gmail bersama-sama untuk membantu institusi pendidikan. Google Kalender kemudian diintegrasikan untuk membantu penetapan tanggal jatuh tempo, kunjungan lapangan, dan pembicara kelas. Google Kalender juga dapat membantu dalam memberikan penugasan kepada mahasiswa dengan lebih baik yang bisa direncanakan secara teratur.

Pelatihan dilakukan dengan mengajarkan secara langsung melalui laptop atau smartphone masing-masing dosen. Dosen diajarkan bagaimana membuka sebuah kelas, menambahan materi kuliah, memberikan tugas, dan membuat kode kelas yang kemudian dibagikan kepada mahasiswa. Selain itu para dosen juga diajarkan membuat quiz melalui google form yang bisa melakukan penilaian secara otomatis, sehingga sangat membantu dosen dalam melakukan proses pembelajaran.

\section{HASIL DAN PEMBAHASAN}

Kegiatan pelatihan dilakukan dengan diawali pemaparan visi perguruan tinggi yang disampaikan oleh wakil rektor bidang akademik. Materi yang disampaikan mengenai pentingnya proses pembelajaran diperkuliahan. Dalam satu semester yang terdiri dari 14 minggu pertemuan. Selama masa perkuliahan diharapkan dosen dan mahasiswa selalu melakukan tatap muka dikelas. Jika terpakas berhalangan hadir dan tidak bisa melakukan penggantian di hari lain maka dosen bisa mengajukan permohonan untuk membuka kuliah online.

Sebelum masuk ketahap pelatihan, pembicara memberikan materi mengenai sosialisasi program Google Classroom. Sosialisasi program dilakukan untuk mengenalkan program dan cara penggunaan kepada dosen ITATS. Dalam tahapan ini juga disepakati tentang komitmen untuk berpartisipasi untuk melakukan pembelajaran secara penuh waktu selama satu semester salah satunya melalui media Classroom.

Kegiatan selanjutnya dilakukan pelatihan penggunaan Classroom sebagai media pembelajaran bagi dosen. Pelatihan yang dilakukan meliputi pembuatan akun Google Classroom, cara membuka kelas dan membuat kode kelas, menambahkan materi kuliah, membuat daftar presensi kehadiran untuk mahasiswa, membuat quiz atau tugas serta cara penilaian.

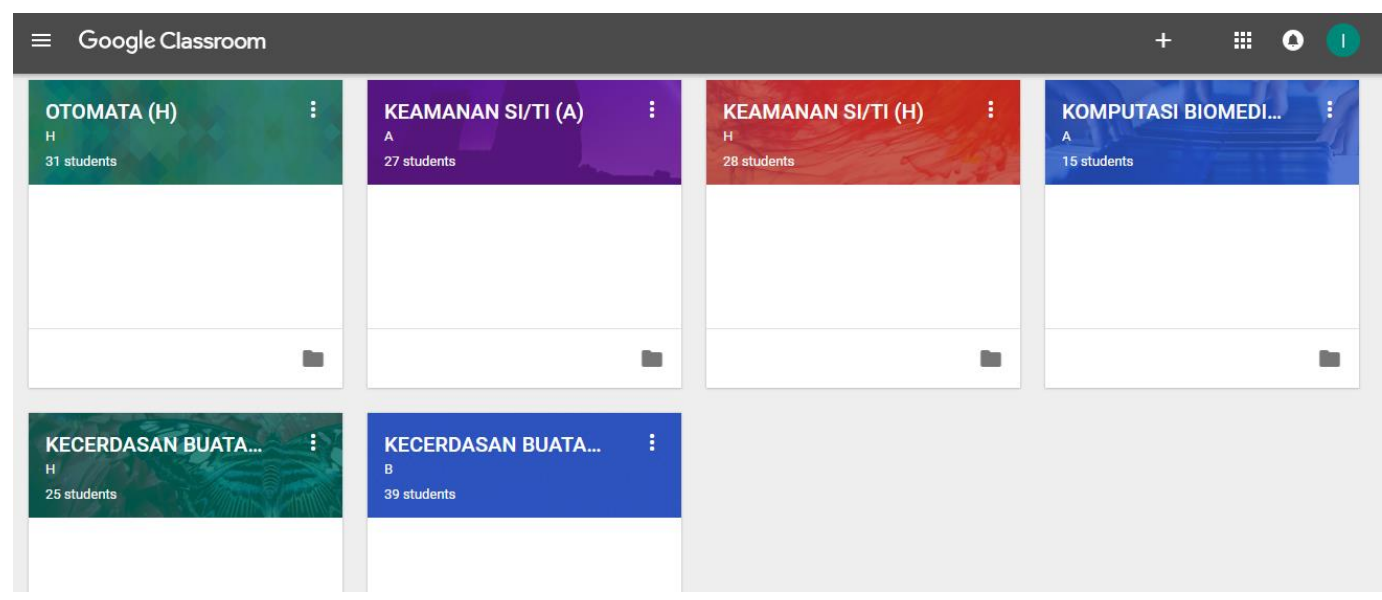

Gambar 1. Tampilan Google Classroom 
Pada pelatihan juga diajarkan untuk membuat kelas kolaborasi, dimana dalam satu kelas pada satu mata kuliah bisa diisi oleh lebih dari satu dosen. Dosen yang memiliki kemampuan di bidang yang sama bisa ikut andil memberikan materi kepada kelas lain. Tampilan google Classroom yang diajarkan seperti ditunjukkan Gambar 1.

Tahapan pelatihan dilaksanaakn dengan tujuan untuk memberikan kesempatan bagi dosen untuk langsung mempraktikan apa yang telah diajarkan oleh pembicara. Dosen mencoba membuat membuka kelas dan menambahkan materi ajar, serta membuat kuis atau tugas.

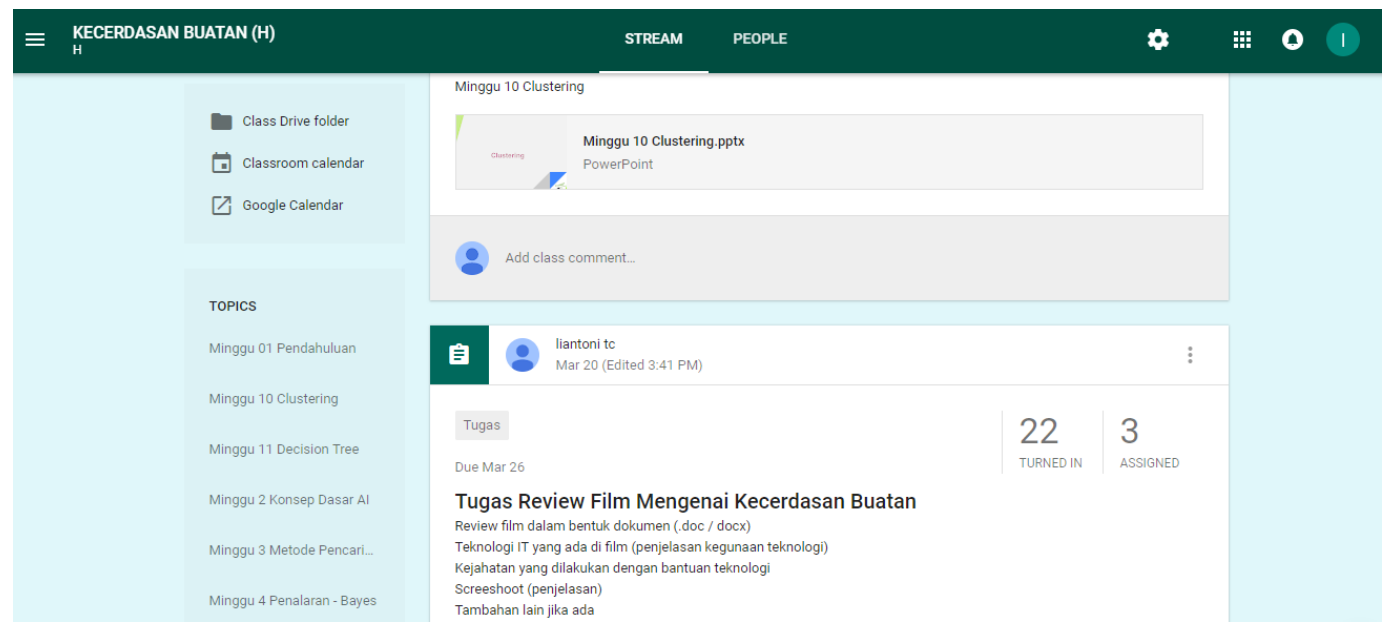

\section{Gambar 2. Tampilan Pembuatan Kelas}

Pada Gambar 2 menunjukkan hasil penambahan materi perkuliahan dan pembuatan tugas. Mahasiswa yang ikut dalam kelas yang dibuka akan menerima materi dan penugasan yang diberikan oleh dosen pengampu mata kuliah.

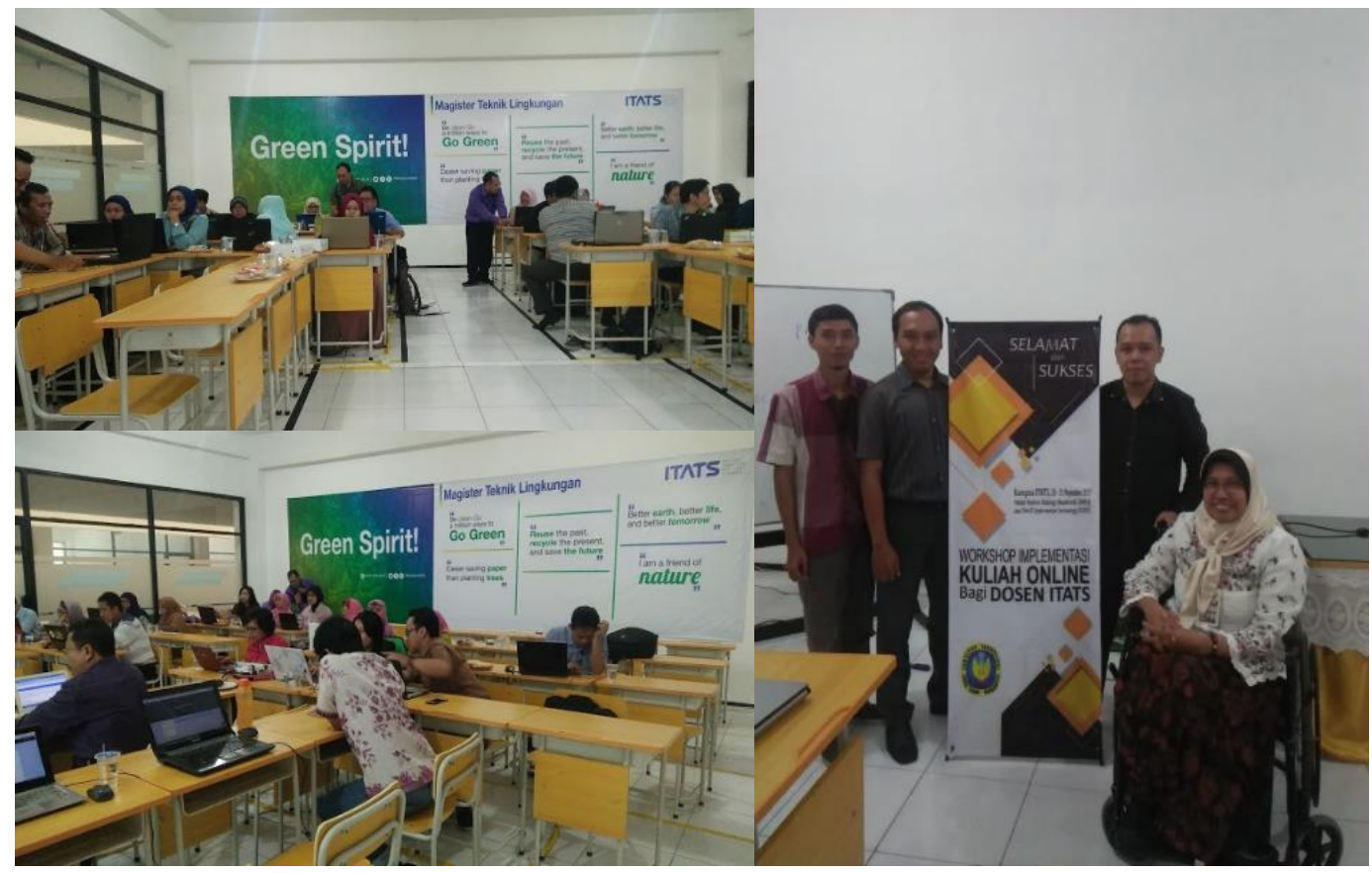

Gambar 3. Pelatihan Penggunaan Classroom 
Pada Gambar 3 menunjukkan proses pelatihan dan pendampingan terhadap dosen untuk menggunakan aplikasi Classroom. Para dosen terlihat antusias ketika mencoba mengggunakan aplikasi Classroom. Pada dosen dapat mencoba sendiri bagaimana membuka kelas dan menambahkan materi kuliah. Dosen juga dapat membuat file berbagi dokumen yang ada di google drive mahasiswa dan dosen. File dokumen yang kemudian dapat diperlakukan sebagai template sehingga setiap mahasiswa dapat mengubah salinannya sendiri. Mahasiswa juga dapat memilih untuk melampirkan dokumen tambahan dari drive mereka ke tugas.

Pada pelatihan juga dilaksanakan tahap dialog tentang pelatihan media pembelajan yang digunakan. Tahap ini dilaksanakan dengan tujuan untuk memberikan kesempatan bagi peserta pelatihan untuk bertanya, bertukar pendapat, menyampaikan ide dan gagasan yang diperlukan dan bertukar pengalaman mengenai kesulitan dalam memahami media pembelajaran yang dihadapi selama pelatihan berlangsung.

Antusiasme peserta pelatihan sangat tinggi selama pelatihan berlangsung. Hal ini terlihat dari semangat dosen untuk mencoba berbagai menu dalam yang disediakan aplikasi Classroom. Selain itu, ditunjukkan banyaknya pertanyaan yang muncul selama pelatihan, beberapa masukan yang disampaikan peserta di tiap sesi pelatihan.

\section{SIMPULAN}

Berdasarkan pelatihan yang dilakukan diambil kesimpulan antara lain: terlihat bahwa para dosen telah menyadari akan pentingnya media pembelajaran secara online selama perkuliahan. Pelatihan kuliah online melalui media Classroom menjadikan para dosen mempunyai kemampuan mengelola materi kuliah dengan lebih baik, dapat menyusun jadwal kuis atau tugas secara teratur tiap minggunya, kemampuan dosen dalam komunikasi interpesronal juga mengalami peningkatan dengan dilakukan kolaborasi kelas.

\section{REFERENSI}

Asyhar, K. (2012). Kreatif mengembangkan media pembelajaran. Jakarta: Penerbit: Referensi.

Buntoro, G. A., Ariyadi, D., \& Astuti, I. P. (2018). Pemanfaatan e-learning quipper school oleh guru dan siswa untuk optimalisasi pembelajaran di MAN 1 Ponorogo. Jurnal Pengabdian Kepada Masyarakat (Indonesian Journal of Community Engagement), 3(2), 153160. doi: $10.22146 / j p k m .27404$.

Eliana, E. D. S., Senam, S., Wilujeng, I., \& Jumadi, J. (2016). The effectiveness of projectbased e-learning to improve ict literacy. Jurnal Pendidikan IPA Indonesia, 5(1), 51-55.

Kurnia, E. D., \& Nugroho, Y. E. (2017). Pelatihan pembuatan media pembelajaran aksara jawa bagi guru bahasa jawa sma di kabupaten Rembang. Jurnal Pengabdian Pada Masyarakat, 2(2), 101-112. doi: 10.30653/002.201722.22.

Muslih. (2016). Pemanfaatan media pembelajaran berbasis ICT pada lembaga pendidikan non-formal TPQ. Dimas: Jurnal Pemikiran Agama untuk Pemberdayaan, 16(2), 215-234. doi: 10.21580/dms.2016.162.1090. 
Sari, S. D. P. (2016). Manfaat media pembelajaran berbasis ICT (information and communication technology) dalam pembelajaran bahasa Indonesia. In N. Suryani (Ed.), Pengembangan ICT dalam Pembelajaran. Paper presented at Seminar Nasional Teknologi Pendidikan, Pascasarjana Program Studi Teknologi Pendidikan Universitas Sebelas Maret, Surakarta, 28 November 2015 (pp. 115-123). Surakarta: UNS.

Sohibun, S., \& Ade, F. Y. (2017). Pengembangan media pembelajaran berbasis virtual class berbantuan Google Drive. Tadris: Jurnal Keguruan dan Ilmu Tarbiyah, 2(2), 121-129. doi: 10.24042/tadris.v2i2.2177. 